\title{
Helping to Build a Sustainable Future through the Greening of Industry and its Networks: Knowledge Sharing and Action Promotion
}

\author{
Joseph Sarkis, Diego Vazquez-Brust, Theo de Bruijn, Kurt Fischer, Maria Laura Franco-Garcia, \\ Somporn Kamolsirioichaiporn, Harn Wei Kua, Martin Lehmann, Ilangovan Kuppusamy
}

\begin{abstract}
The Greening of Industry Network (GIN) is into its third decade of involvement in integrated environmental, social, and economic debates. This paper introduces GIN to another generation of thinkers and doers, and reintroduces it to participants who have had previous experiences with GIN and/or its activities. GIN's history and the various 'debates' sponsored by the organization over the years will be overviewed. We also identify debates and directions that we see continuing or emerging over the next few years, as GIN continues to evolve. Although GIN has been an active player in the debates about the greening of industrial development for two decades, it has evolved as social, technological, organizational, and economic developments changed. Over its two-plus decades, GIN has seen significant shifts in a number of directions, many of these shifts occurring in sporadic and unexpected ways. Climate change, resource depletion, sustainability, technological change with an expanding global communication network, social media, multiple recessions and growth periods, base of pyramid emphasis, a growing academic stream in business and the environment, have all contributed to the various lenses of GIN participants and thereby shaped action and activities in the Network. Change continues. GIN will be there to help understand and address some of these changes as they pertain to the Greening of Industry.
\end{abstract}

Keywords: Greening of Industry, Environmental, Conferences, Knowledge Creation, Knowledge Sharing, Multi-Stakeholder, Organizations, Non-Profit, Sustainability 


\section{INTRODUCTION}

The Greening of Industry Network (GIN) is connecting professionals from research, education, business, civil society organizations, and government. GIN focuses on issues of industrial development, environment, and society, and dedicated to building a sustainable future. Founded in 1992, GIN is the oldest active academic network on organizations and natural environment.

This paper focuses on the organization, its goals, and the various debates sponsored by the organization over the years. As members of the GIN coordinating team we also identify debates and directions that we see continuing or emerging over the next few years, as GIN gathers full steam in its third decade. Although research ideas are prevalent in this paper, it is not meant to focus on specific research questions but serves as a dialogue, viewpoint and opinion vehicle. The purpose is to position the broader works of this special issue within the context of the history of GIN, a major sponsor of the special issue and the conference from which papers in this special issue are derived.

Over its two-plus decades GIN has seen significant shifts in a number of directions, many of these shifts occurring in sporadic and unexpected ways. Climate change, resource depletion, sustainability, technological change, an expanding global communication network, social media, multiple recessions and growth periods, base of pyramid emphasis, a growing academic stream in business and the environment, have

all contributed to the various lenses of GIN participants. These issues have affected previous GIN debates and we believe GIN debates have influenced some of the thought in these areas.

GIN has evolved with at least three generations of academics, industry, and government representatives involved. Right from the beginning we have had participants who were mature thinkers on these issues; these thinkers began GIN. There are some of us who grew up with GIN and are still participating. Now, the third generation is made of new scholars, industry participants, and government officials who are experiencing debate initiation. Not every GIN participant can be pigeon-holed into one of these generations. But, for a successful network we need these various participants involved. 
At one time there was concern on whether GIN had outlived its usefulness, but even a 10- or 20- year presence of trying to influence a global sea-change in thought and practice is not possible. When dealing with the relationship between human development, industry, and the natural environment measurements and a focus on decades may still be myopic. Sustainability deals with focusing on generations and inter-generational relationships. Change continues. The economic behemoth that is China, future technological developments, uncertain political and economic winds, the renewed understandings for the concept of sustainable development, the further globalization of academic research, the growth of the super corporation, philanthropic activities, and the continuing crises in population and climate sciences, may all play a role in how GIN guides its debates. GIN requires the flexibility to be able to identify, research, discuss, and communicate various concerns whether they are local, regional, or global in scale.

The place of GIN conferences in the field with respect to other conferences has always been a practical focus on policy implications of academic research. "GIN is the most practice-focused of pioneering networking organizations and represented a foundational impetus for increased attention to environmental issues".(Rands and Starik, 2009, 24). GIN is a networking and alliance formation organization. From its first conference, back in 1992, GIN has always sought to bring together government, business, and academic scholar in the sustaincentric quest for re-integration of environmental issues in policy concerns.

Therefore, an important functional aspect of GIN is the need for collaboration. Collaborative efforts across sectors of the 'triple-helix', collaboration amongst generational levels, collaboration across disciplines, and collaboration across regions of the world are necessary for healthy progress and debate. These collaboration examples are evident in many of the projects and programs GIN has sponsored over the years (see for instance De Bruijn and Tukker, 2002). Collaboration will need to continue as we dialogue and debate across the various boundaries we encounter as it pertains to complex industry and environment issues. The future of collaboration and how GIN manages collaboration (networks), knowledge development and its use are important concerns addressed in this paper.

The paper is structured into three major parts: GIN's past, present and future, followed by a conclusion. Section 1, the past, presents a history of the GIN network, discussing contributions of GIN 
conferences to the field of sustainability and its relation with policy debates. Section 2 , the present, describes GIN today, its resources and activities. Finally, Section 3, the future, looks back to GIN's 20 years of experience, reflects on current and future challenges for the sustainable development movement in general. Challenges for GIN in particular are discussed. Finally this paper sets the stage for debates ahead.

\section{OUR PAST: GIN - A HISTORICAL PERSPECTIVE}

In the 1980's three globally defining, but regionally occurring industrial environmental disasters set the stage for the industry and environment relationship awareness. These were in turn, the Union Carbide Company's Bhopal disaster, India, December 3, 1984; the Chernobyl nuclear disaster, Ukraine, April 26, 1986; and the Exxon Valdez oil spill, Alaska, United States, March 24, 1989. These disasters represented punctuated equilibrium events that generated a sense of urgency and traction for a global sustainability agenda (Dryzek, 1997). A further, positive defining event in the 1980s was the publication of Our Common Future by the World Commission on Environment and Development (1987), known popularly as the Brundtland Report.

GIN is a virtual organization without formal rules, membership, structure, or regular finance. Set out in 1990 by its founders, Kurt Fischer and Johan Schot, the initial goal was to engage about 200 activists as the GIN core. Their initial goal was to change the way knowledge leads to action, by connecting people through work and ideas across professions and national boundaries. GIN's efforts include constructing research agendas and stimulating high quality research to inform policy, strategy and actions. GIN has consistently grown over the years with hundreds of active participants and thousands of interested parties. Participant characteristics and involvement have shifted through GIN's permeable boundaries. Participants' level of activity is dependent on many functions including their relative interest and issues that are on the GIN agenda. Although currently we have a coordinating team, our management and planning is as fluid and organic as the organization.

Publications, conferences, and workshops with their ephemeral linkages have contributed to GIN's fluid existence and organizational progress. Over the past 20+ years, GIN sponsored or co-sponsored 33 events (see Table 1). 1991 was the year of the first GIN Conference in The Netherlands: The Greening of Industry: 
Research Needs and Policy Implications was the theme. It was followed by a landmark year for Sustainable Development Policy: with the Convention on Biological Diversity Protocol on Biosafety ("Cartagena Protocol"); The United Nations Conference on Environment and Development (UNCED / "Earth Summit"); and the Framework Convention on Climate Change (UNFCCC) (Kyoto protocol), setting the sustainability agenda for the next decade. Over the years there have been more milestones related to international efforts that have sought to address various environmental concerns. Treaties, conventions and protocols all contributed to the dialogue and efforts for managing environment and industry. A listing of some of these initiatives that parallel the growth of GIN, and slightly preceding GIN development but also influencing the debates are listed in Table 2.

\section{$<$ Tables 1 and 2 about here $>$}

In the early years (1982-1987) before the beginning of GIN, the industry influences were from products they manufactured and their operations. For example, the issues with the ozone layer were greatly influenced by products and materials related to hydrocarbon emissions and regulations limiting ozonedepleting emissions started affecting industry. These concerns also led to industrial innovation. Realizing the increasing roles of industry, government, and NGOs in this period further catalyzed efforts by GIN. In 1987, the influential "Our common future" involved industry and its stakeholder relationships with the other triplehelix partners of GIN. It was after this time in GIN from 1991-1995 that the term sustainability and sustainable enterprises were initially being utilized. Environmental aspects were an important aspect, but GIN was early in expanding on the definition and utilization of sustainability.

In the early and mid-1990's biodiversity, climate change, and desertification (natural resource depletion) were all a focus of international treaties and events. GIN, was still focusing at this time on alliances, networks, and joint efforts to address these and other issues. The additional dimensions of environmental sustainability made the need for greater partnership formation and regional development activities. The regional and partnership focus, along with the relationship between economics and environmental issues, green growth, was nascent during this period and continues to grow today. 
It was a given that this period saw a shift in thought concerning the relationship between economics and environmentalism within industry, government, and academia. Although a critical eye on this relationship was maintained, no longer were these two dimensions of development considered trade-offs and always in conflict (Hajer, 1995). Motivating industry through coercive regulatory measures was viewed as only one set of policy instruments for helping industry achieve and meet environmental goals; flexible and market based policy instruments began to gain traction and support (Porter and van der Linde, 1995). Businesses became less defensive about the environment-economic link, with this philosophy maintaining great interest even today. The agenda also broadened considerably from environmental management towards the broader concept of sustainable development and industrial transformation (De Bruijn and Norberg-Bohm, 2005).

As with every dynamic situation, the morphology of this environment-economy relationship has gone through various evolutionary and sometimes de-evolutionary stages. Sometimes these stages evolved out of perceived necessity, for example recessionary forces during this period causing declining green investment. Sometimes the evolution occurred from strategic planning initiatives by individual organizations and industry. For example, British Petroleum in the early 2000s abandoned their efforts to be noted as the 'Beyond Petroleum' company when a change in company governance and leadership occurred.

Natural environmental issues as a potential competitive market weapon gained interest in industry, building the business case for greening industry became ingrained business parlance. With very high profile articles in the Harvard Business Review and other top practitioner oriented academic business journals, there arrived broadened acceptance that 'win-win' opportunities were the best way to achieve joint environmental and economic success. Even more recent conferences in GIN and the Rio+20 Convention focused on the topic of Green Growth, where the business case is still being made at the broadest macro-economic levels. In this Green Growth paradigm the decoupling of environmental burden from economic growth is part of the win-win (or at least win-“do-not-lose") argument where environmental investment is advocated as a driver for economic growth and a way out of recession (Vazquez-Brust \& Sarkis, 2012; Jacobs, 2012; Lorek \& Spangenberg, 2014). 
Technological solutions, technology, industry, and environment relationships, were part of the early and continuing debates in GIN. Technological solutions were thought of as solutions for decoupling environment and economy, win-win propositions, and making the business case, discussions. Some of the initial developments associated with ecological modernization theory that stipulated the role of technology as a solution to decoupling occurred during the early years in governmental policy discussions (Jänicke, 2008), and in later years as business policy discussions. Although, some did, and still do, see technology as machine only, an undesirable intrusion in nature (Giddens, 1990), while others saw technology as an expression of human values and culture, encompassing human creativity and organization ( Martinez-Allier, 2002). This debate continues.

Simultaneously, during this past 20 year period, the growth of sustainability discourse and triple (economic, environmental and social) bottom-line (TBL) thinking as dominant paradigms in environmental issues was also occurring (Jacobs, 2012). These topics had a profound impact on GIN debates as the shift in debates incorporated 'beyond greening' issues that flowed over into broader social dimensions associated with TBL thinking. For example, the bottom (base)-of-the-pyramid (BOP) debate had a significant presence in GIN conferences since 1999. The question that arose was whether BOP, with multinational's targeting the poorest people, is serving or exploiting the poor (Jenkins, 2005). The GIN debate generated much heat as this BOP 'work-in-progress' evolved and continues to evolve (Sarkis and Gollagher, 2008). In some ways, the debate also included whether we should be so explicitly focused on these broader social issues which may envelop and hide particularly important environmental greening issues (Sarkis, 2007). The extra dimensions of sustainability and the inter-generational philosophical facets made for interesting discussion, but in some arenas it was cynically viewed as a way for industry to take advantage of the tradeoffs associated with the TBL dimensions. Less cynically, business and other stakeholders felt that these dimensions caused greater complexity in planning and management for the long-term and answers were needed.

Sustainability as a discourse topic also generated a broader emphasis in North-South relationships and sustainable global development. The framing of such relationships has evolved from top-down knowledge transfer to reverse knowledge; and from North-funded donor schemes to third sector initiatives unleashing the 
potential of the South such as the Honey-Bees movement and Grameen Bank. This debate around the sustainability stream continues today as South to North environmental innovation and sustainability in the Global South is a topic of a recent Springer GIN book series.

During these past twenty years, evolution and growth in GIN also contributed to the broader growth in industry and environment discussion and development. One primary example is the influence of GIN participants on the initiation and eventual growth and development of one of academia's more influential professional groups. The Organizations and Natural Environment (ONE) division of the Academy of Management can trace some of its beginnings to early GIN conferences. Academic GIN participants initiated planning for an academic group to address industry/environment linkages. ONE has grown to over 600 academic members, just from the management discipline.

In research, the International Human Dimensions (of Global Environmental Change) Program on Industrial Transformation (IHDP-IT) found many people assembled within the Network for its scientific committee. In higher education, the international $\mathrm{PhD}$ program at Erasmus University Rotterdam often convenes its annual residency retreat around the Network conference, using it as a unique teaching experience, which continues to this day with the GIN conference in Linkoping. Many GIN participants were also involved in the establishment of the Sustainable Consumption Research and Action Initiative (SCORAI), which sponsored its fourth conference at Clark University in June, 2013.

In policy, agencies such as the U.S. Environmental Protection Agency, US-Asia Environmental Partnership (USAEP, a project of USAID), Asian Development Bank, Environment Canada, the Environment and Research Directorates of the European Union, the Dutch Environment Ministry, and UNEP have all sponsored GIN at some time and used it to gain new knowledge and develop new approaches. GIN has facilitated the development of joint research proposals for the Framework Programs of the European Union. In the past business representatives from companies such as General Motors R\&D, GE Capital, Polaroid, Toyota, and Novo Nordisk have found the Network to be a unique resource, a sounding board and listening post for their strategies for sustainable development and corporate greening initiatives. 
During the early period, GIN participants and ideas had limited outlets for publishing findings. But, since these early years of few academic and professional publishing outlets focusing on greening industry, the number of academic journals has blossomed. Also, the number of publications focusing on this topic has increased exponentially. For example, in the early years of ONE (the early 1990's), and on their website, only a handful of articles by ONE members are listed. Within a decade hundreds of published articles can be found from ONE members in some of the most influential journals in management and engineering.

GIN has had relationships with a number of publishing outlets over the years including Business Strategy and the Environment, the Journal of Cleaner Production, Management Research Review, Island Press, Greenleaf Publishing, and Springer Publishers, to name a few of the GIN publishing partnerships. Publishers and publishing outlet relationships are central to one of GIN's objectives associated with dissemination of knowledge. The conferences represent the source of raw material of knowledge; the publications represent the refined product of knowledge to be consumed for further growth of this important field.

The other evolution in this time period that has profoundly affected the growth and evolution of GIN is the Internet (World-Wide-Web) and social media. GIN has had a presence on the Internet almost from its very beginnings. The electronic repository of GIN material has been an important resource for many stakeholders as evident by responses to a survey of GIN participants in 2007. Easy access to previously published information on GIN topics has been a valuable resource for industry looking for best practices, government officials for helping with policy decisions, and academics looking for theoretical underpinnings and recent developments. The continued management and inexpensive availability of this emergent information is expected to remain a service that GIN provides to all its past, current, and future participants.

GIN has grasped social media and continues to do so with professional social media as LinkedIn. Although virtual conferences have not occurred at this time, in the future more possibilities will exist as the technology matures and becomes more reliable and effective. All these latest virtual approaches for networking will be evaluated as technology and information dissemination continue to develop. 
During this period GIN faced many challenges, many of which are still faced today. There has been growth in a number of business and environment focused organizations, conferences, and interest groups. The breadth of GIN participants has been able address this issue by allowing for cross-sector communication and knowledge sharing. But, that characteristic may also be putting GIN as a secondary source of knowledge and collaboration since most participants will focus on their primary interests (e.g. academic, governmental or NGO). There were some challenges in identifying and supporting conferences and workshops to maintain a consistent pattern of offering them. This challenge was finding interested parties who had the resources to be the leads in organizing and offering the meetings. GIN, with its volunteer leadership group, has limited time and resources to run these conferences without support of local parties willing to central organizers the local effort. Another continuing challenge is to maintain and update the communication and knowledge sharing during 'off-periods' between conferences. Managing the websites and newsletters, in addition to various listings of members and interested parties, is a continuing administrative and networking issue. Since the organization is all about networking, these are critical resources that require careful management. As program directors and coordinators evolve passing on the organizational knowledge and practices is a major challenge as well. Some of these issues are addressed discussed later with various efforts identified.

\section{OUR PRESENT: GIN TODAY}

At this time, GIN is managed by a team of nine coordinators, which we define as the coordinating team. Over the years GIN has evolved its governance structure that included three primary coordinators, a strategic planning committee, and an advisory committee. Eventually, due to the voluntary nature of all involved it was decided that a single larger coordinating team be formed. The coordinating team comprises of nine volunteers from throughout the world. Discussion and participation are primarily through electronic means and at GIN events. GIN is always looking for volunteers willing to increase their participation to a coordinating team level.

\section{GIN CURRENT ACTIVITIES}


The most important GIN goal and characteristic is communication and knowledge dissemination across networks. The bedrock of communication is through the organization's website (www.greeningofindustry.org). The website is updated as frequently as possible and remains a challenge as new technologies, practices and designs are implemented. The website is utilized it to capture information. Readers are encouraged to visit the website and contribute to its further development through comments. On the homepage of the website, there is a place for email and name. Entering data is all that is required for someone to become a GIN participant. The website not only contains latest announcements and events descriptions, but also a publicly available archive of the many GIN publications and conference proceedings, some that are not found anywhere else. Our respondents to a survey delivered in 2007, felt that this type of easily available archived information is one of the greatest values of GIN, but requires maintenance.

The coordinating team's communication effort also includes the monthly delivery of a brief newsletter on GIN activities and information. This newsletter helps update the network on various thoughts and pursuant activities. It also maintains an updated relationship with GIN participants. Readers' comments on how to improve this distribution channel are always welcome.

There is now a formal LinkedIn group for GIN. This group has been in existence for a some years and has undergone further expansion with the membership and debate topics growing. Other social media avenues were considered, but maintaining a professional image was important. LinkedIn is the social media outlet we are currently utilizing. Please join us as the group continues to expand and also integrate other social media such as Twitter.

Participant management is a critical issue faced by GIN. GIN would not be a network without its participants. The communication channels help to keep participants updated on various events and new ideas and publications. The major draw for new participants has always been the GIN-sponsored or co-sponsored conferences and workshops. Our conferences are selected such that they switch venues over the years. Conferences and workshops are schedule to appear on different continents. Major conferences have occurred at approximately once every other year, while workshops 'fill in', in between. The strategy is to support local organizers through the network and which keeps GIN a truly international organization. 
According to the last GIN survey, from over 5 years ago, assuming a random response, the major (over 75\%) group of participants are academics. This result is not surprising since most of the coordinators are from academia and that publications are a major dissemination practice. Business participants represent 22\%, government and NGO participation has been at $11 \%$ and $10 \%$ respectively. Yes, the numbers do add up to greater than $100 \%$ which means that some of our participants have more than one sector affiliation (for example Ph.D. students who also work in business or government). The 2012 conference in Linköping showed a very strong presence of the three major groups with presentations and discussions among them.

Currently, there are a number of publication initiatives in process. This special issue in the Journal of Cleaner Production is the major outcome of the 2012 Linkoping conference.

We also have an official relationship with the Springer Publishers, who have sponsored a book series titled Greening of Industry Networks Studies. The series will be an integral part of GIN-3D (Greening of Industry Network Third Decade) strategy and the series editor and editorial board are comprised of the GIN coordinating committee. Already five books have or will be published in this series. One or two additional conference debate topics are expected to be in process over the next year. All readers and GIN participants are encouraged to submit proposal ideas, contact any of the coordinators for more information.

\section{OUR FUTURE - THE GIN ORGANIZATION AND FUTURE DEBATES}

In this final section, we will peer into GIN's future. Insight into possible directions for our participants, communication, and publications are also presented. Some continuing and emerging debates with reflection are also briefly presented.

\section{The Future of GIN, the Organization}

A key challenge that requires GIN participation is continued action and advocacy in the fight for prominence, visibility, relevance, and urgency of green issues in the political and academic agendas. New ways to engage communities - especially industrial communities - and policy-makers are needed since, as Jacobs observes, "the concept of sustainable development has had decreasing traction on economic 
policymaking over recent years [ ... Moreover, it became clear that countries' apparent commitment to sustainable development had not been sufficient to reverse the historic decline in the health of the global environment which had led to its invention: almost all significant global indicators have continued to worsen" (Jacobs, 2012, 6). We believe that GIN needs to help create connections, develop knowledge, facilitate learning, and secure action.

Given that human resources are very precious, repeating what others have been or are doing seems to exhaust this resource unnecessarily. An issue is how to bring something new to the conversation and debate. More effectively carving out a niche for GIN is required. At the start of the Network, GIN was unique, and therefore broad in focus. Currently with so many networks and venues for debate there is a need to define GIN's focus more closely. Bridging the gap is a valuable differentiator, the 'Roots of GIN' that needs to be further embraced. GIN needs to create more bridges to connect with industries, and bring actionable concepts to them, in the form of tools or management plans. Or at least, provide a venue where industry can provide insights into how theory has been applied.

GIN will seek to provide venues for disseminating new theories and also converting these theories into practical strategies that may or may not be unique to industries, such as, tourism, mining, fisheries, forestry, food and beverage, manufacturing, education, $R \& D$, and defense. A major direction is to engage these stakeholders in a variety of platforms. GIN will support more action research activities that encourage very practical developments in real organizations, applying theory, and actually observing and sharing these findings, for example, expanding on similar efforts as Kua (2010).

GIN will be utilizing more of social media, newsletters, websites and blogs for virtual communication. We realize that in this information-based economy, and information-based lives, the amount of information overload can increase greatly. Thus, careful targeted GIN-based activities and issues will need to be administered. GIN is a non-profit that has been managed by volunteers since the beginning. Maintaining this organization, 'on-the-cheap', has been a major effort. The use of social media and virtual setting may help alleviate the costs and inconveniences of logistics that are risks to the 
continued success of GIN. Having a larger geographically dispersed group of program coordinators in GIN has helped to maintain this success. The group includes both veteran participants and newer participants that keep the lifeblood of new ideas and programs evolving. These activities are not trivial and require consistent motivational and resource infusion. The incentive mechanisms are intrinsic to the individuals who run and participate in GIN. It is this intrinsic motivation that needs to be built upon.

As part of these efforts GIN will need to develop a broad research agenda for its third decade, and maybe beyond. This agenda will be connected to new developments in learning and education, to our publication and knowledge dissemination strategy and a strategy for outreach/engagement. The major way this is accomplished is through our workshops and conferences. Offering a bit more in the conferences to build on the intrinsic motivations of continuing and future GIN participants is through conferences and workshops.

\section{Conferences with a Purpose}

GIN conferences are critical to the network and community building that GIN has endorsed, even from its beginning. We cannot stand idly by and be venues for scholarly debates that no longer thrive. One critical aspect that can be further developed is incorporating social outreach within GIN Conferences. This outreach will ensure that new knowledge creation is disseminated and applied to communities beyond academia.

A future goal is to make meetings and conferences relevant to the community, especially in those which host the conference. Engaging with local agencies and creating new perspectives and solutions will be a key to local impact. Ideas as simple as food donation can make a difference. More broadly encouraging and requiring collaboration with local companies will be a goal. GIN can become a platform for synergetic activities. Examples may be to include GIN conference events such as inviting school children to attend a special exhibition or even development of an environmental quiz. Having GIN conference organizers involved with local schools or agencies as collaborators, is part of a planned community outreach activity. GIN participants can contribute by developing quiz questions, or presentations targeted to future generations. This is just one way to "put GIN out there" and play a more active and visible role in disseminating knowledge. We 
seek to disseminate knowledge beyond the core academic circle of interested parties and go well beyond 'Preaching to the Chorus'.

In the past, GIN targeted a local or regional urgency. For instance, in 2002 GIN co-organized a workshop in Chelyabinsk, Russia, jointly with Women in Europe for a Common Future, and a Local Organizing Committee (with representatives from Russian NGOs, regional authorities, business and Chelyabinsk State University). This heavily polluted region was seeking a new sustainable perspective. Experts from the Network helped in facilitating the dialogue between different groups. Jointly a program consisting of concrete activities was designed. In 1997 GIN completed a similar activity in Puerto Rico. In 1998 GIN focused on addressing ways out of the financial crisis that affected Asia, at a regional conference in Bangkok. Through regional meetings the Network was able to not only debate general concepts but also address specific needs of the community. This strategy of co-organizing focused meetings will be revived.

GIN conference organizers will be encouraged to leave something of value behind for the community - something that the community can develop on their own after GIN leaves. These activities will include provisions in conferences for interacting with local society that was just visited by hundreds of exceptional and bright people from GIN. For example, at the Linkoping conference, "jam sessions”, were sponsored where conference participants went to various organizational sites to help brainstorm solutions to sustainability problems for these organizations.

GIN needs to ensure that the knowledge that was embedded in a conference gets out and gets to work locally, regionally, and eventually globally. We will encourage conference planners and participants to creatively provide insights and innovative ideas for these types of practices. Practices that can be learned and shared with future GIN participants.

As proponents of greening efforts overall GIN will ensure environmental sustainability of GIN conferences. We need to make sure, double down, on conferences meeting a GIN sustainable meetings protocol. This will require some basic requirements and goals set forth by GIN organizers and planners (inspired by http://www.visitdenmark.com/international/en-gb/menu/mice/news/csmp/csmp.htm). We need to expand some of the initial measures of earlier conferences that sought to maintain green and sustainable 
operations, a "Greening the Greening conference." GIN needs to encourage and require this for future conferences.

\section{The changing focus of the sustainable development movement and GIN's role: Looking back at 20 years} of GIN

When GIN began the focus of the sustainable development movement was on internal organizational performance. Environmental themes were peripheral to mainstream academic research. Conventional management and economic theory was underpinned by a fractured epistemology that separated humanity from nature and truth from morality (Gladwin, Kennelly and Krause, 1995). This dominant paradigm and silothinking also constrained natural sciences approaches to environmental and social issues. Since that time natural sciences, sociology and economics have coalesced to develop sustainability science, a growing paradigm that proposes a cohesive epistemology where nature, humankind, truth, and ethics are seen as interdependent. At the same time, conventional management theory incorporated environmental and sustainability themes through institutional, agency and stakeholders theory (Sarkis et al., 2011).

Preferred policy solutions shifted from mandatory to voluntary approaches, from in-company to extended networks, and from national to "glocal". Corporate social responsibility and voluntary standards (e.g. GRI, ISO 14001, ISO 26000) increasingly became the sanctioned approach to deal with environmental problems in organizations, which are based on voluntary approaches and self-regulation. Reflecting on the challenges that this growing complexity brings to GIN is a priority and an on-going process of GIN stakeholders and conference organizers.

One reflection is the contested nature of many dominant solutions and the need for GIN to sustain a focus on core values while providing an unconstrained arena for debate of policies and alternative solutions. There is a need to be more explicit in terms of what those core values are and how they define epistemological boundaries. This explication does not mean that GIN will not bring new and relevant topics into the arena for debates. On the contrary, we should be alert and willing to do it, but we should be careful in terms of endorsing one alternative over others and creating discursive "black boxes" where alternatives cannot be discussed. 
The GIN mission is not to achieve consensus on "best practice" but create a space for interdisciplinary deliberation and dissensus to meet and dialogue. An important issue for further discussion is to what extent this arena, GIN, should be only for like-minded individual sharing core beliefs, as it has been up to now.

Networking beyond the 'choir' is needed. Bringing in less environmentally and sustainability oriented thought leaders into the discussion are necessary. There should be caution on allowing and considering the extent on views underpinned by other values are introduced and discussed. In practical terms, for example, would it be possible to support a GIN conference themed "Climate Change: Myth or reality", or it is betrayal of GIN values just allowing a space for climate-changes deniers to voice their views? Do we bring in opponents and cynics of biodiversity? These are real concerns and will dialogues among those with opposing viewpoints allow for greater acceptance of various principles or will there remain a polemic divide?

Looking back to 20 years of GIN, four core beliefs seem to underpin GIN's past and will be its future: the need and ethical responsibility to protect the environment as a priority, the need to understand better the interdependencies between human and natural environment, the need for collaboration at local, regional, national and global levels, and the need for holistic theory and interdisciplinary activity.

Agency is a case in point. Discussion of voluntary approaches and win-win strategies have been part of GIN debates for the last decade, but GIN has never excluded regulation from the discussion. The focus has been on the need for regulators, companies and communities to collaborate and decide the best "portfolio mix" when win-win does not work. GIN's triple-helix approach is now more relevant than ever. The triple-helix approach has allowed GIN some flexibility to help it maintain success in maintaining the debate, but also allowing room for other organizations thoughts to be included. Although much of the discussion and management of GIN has been through the academic community, part of the success of the conferences and workshops was through active inclusion and encouragement of other stakeholders. Unfortunately, maintaining a consistent group of contributors is harder for the non-academic groups, requiring us to reflect on how GIN can provide greater benefits to these non-academic stakeholders.

As in-company adoption grows and there is wider availability of empirical data, there is also more research challenging the usefulness of voluntary approaches, standards and CSR to prevent environmental 
deterioration and create social cohesion (see for instance how grassroots movements and critical management studies frame CSR and ISO 14001 as the toolbox of neo-colonialism). "Post 2015" policy debates are now converging into the idea that voluntary approaches are not the solution, but they are a part of the solution. As argued by Delmas and Montiel (2008) voluntary standards, regulation and community initiatives should not be treated as alternatives but rather as complementary.

\section{Future Debates}

Given these reflections, there are many directions for future GIN debates. An underlying question is whether GIN should keep debating the same debates. If new debate directions are to be taken, does GIN set the debate agenda or respond opportunistically to emerging debates? Here are some of our thoughts.

The debate on why sustainable development is seemingly not working continues. Many critics point to institutional and political barriers for this lack of progress, rather than lack of theory and tools. Summarily, we know what should be done but we are not doing it. Vested interests and ingrained practices seem to co-opt the operationalization of sustainability agenda taking advantage of its ambiguities.

At the same time, we have not taken sufficient stock about what we have thus far learned. In a GIN sponsored workshop organized in 2005 at the University of Twente in the Netherlands, this question and another central question was discussed: what has 15 years of sustainable development debate resulted in? The need to fully address this question still remains. Additional questions still remain, including: What did we learn? What practices have changed? Or have we mostly found new words to address the same issues?

Voluntary participation of industry actors is found particularly wanting. For some, the solution is Green-Growth, a policy focus for sustainability claiming that environmental protection can and will be a driver for growth, provided that the State takes the lead to implement cross-border standards and incentives. GreenGrowth theoretical foundations are relatively untested. In particular, what extent can state-centered policies be adapted to countries with varying political systems? If structural changes are not completed, Green-Growth can end up being little more than a new slogan, a political - rather than business-led- greenwashing aimed to bring the state back into the drivers' seat. 
Understanding the roles of how consumers can drive Green Growth in the right direction is important. Specifically, decisions made by individual consumers as a result of certain sociological and psychological traits must be better understood and applied to Green Growth strategies. This application is needed to prevent Green Growth from becoming a developmental trend that merely delays the onset of negative effects on global sustainability instead of mitigating these negative effects. GIN should be vigilant of the trajectory of Green Growth by identifying successes and best practice but also challenges and threats to the integrity of ecological agenda. An open mind is also needed, to screen and identify alternatives, to bring an arena where more peripheral discourses can contribute to the debate.

A second area for GIN strategy and debate is policy and management practice paradigm change. From a normative perspective sustainability is a radical and innovative concept. Ideas such as the TBL and the precautionary principle are warmly supported as theories of what should be done. However, from the operational perspective, a mindset shift takes place and balance gives way to hierarchies where economic and political aspects have prominence. Despite rhetoric, the discourse is not grounded on institutions. Sustainability policies and ideas are still technocentric in nature, firmly engrained in nineteenth century economic and legal thinking and twentieth century business models. There is hence a need for integration of socio-economic factors into mainstream strategies to bring the concept of sustainability into business practices.

The third set of challenges relates to developing countries, both transitional and emerging economy nations, and least developed countries. These countries are experiencing most of the increase in population and consumption that is making climate change irreversible. Ideas and policies developed by the academy and industry have emerged from developed countries. It is still assumed that all other countries will just have to adapt and follow the wisdom developed through the centuries of industrial development and destruction of natural ecosystems from the North. Again, rhetorical claims are made for bottom-up, integrative approaches to give voice to the concerns and realities of South countries. However, a cursory glance at the contents of leading academic journals reveal little weight given to publications based on data and ideas from these countries. 
A final challenge is implementation. GIN has never been about the academic debate only. The GIN mission states that GIN develops knowledge and transforms practice to accelerate progress toward a sustainable society. The aim for the coming decade of the Network will be precisely that, how to engage with societal partners in such a way that practices will actually be transformed.

These are macro-level debate questions. Within these challenges and queations many additional debates will evolve and regenerate. Practice and research, new theories and insights, will be introduced whether they are by GIN participants or outside of GIN. We are attempting to forecast the future debates, some may believe this is futile, but identification of the debates and issues lays the foundation to determine solutions for current issues. As new greening issues arise flexibility and acceptance of new thoughts and ideas is necessary.

\section{CONCLUSION}

The Greening of Industry Network is well on its way to commencing its third decade of existence. Many of the same people and organizations who were participating from the initiation of the organization are still actively involved. But, many new faces have also joined. During these past 20 years developments and progress has been made through the network, not without challenges and much work still lies ahead. GIN has always been a multi-stakeholder organization and will continue to be so.

This article had a number of objectives. First we helped existing and long-term participants see a clearer picture of where we are and where we have been. To new participants new insights and knowledge of GIN, its history, activities, and resources are presented. Third, not only did we place GIN amongst the previous and current debates, we also attempted to set the stage for future debate. Some of these debates are meant to help industry, government, and academia find ways to work together, to cooperate and continue to network. These debates will occur in face-to-face situations, through electronic means and through publications. In summary some of these debates and future GIN issues include:

- Expanding the inward focus of organizations and agencies to a more complete outward focus. 
- Allowing sustainability critics to be involved and encouraged to dialogue.

- Expanding GIN's goals and philosophies to not only be a venue for debate, but also a venue for practice.

- Whether applying new and emergent theories are needed and can be applied.

- How do we get more involvement from emergent and developing countries?

- Does a technocentric based ideology alone work for integrating sustainability?

In addition to the debates we hope to support actions, whether locally or more broadly. Participation and knowledge development and sharing will continue to be the goals of GIN. We encourage the readers of this journal and this article to be active participants in these activities and in GIN. 


\section{References}

Darnall N, Potoski M \& Prakash A. 2010. Sponsorship matters: assessing business participation in government- and industry-sponsored voluntary environmental programs. Journal of Public Administration Research and Theory 20, 283-307.

Darnall N \& Sides S. 2008. Assessing the performance of voluntary environmental programs: does certification matter? Policy Studies Journal 36, 95-117.

De Bruijn de, T.J.N.M. and Tukker, A. 2002. Partnership and Leadership; Building alliances for a sustainable future. Dordrecht: Kluwer Academic Publishers, Dordrecht.

De Bruijn, Theo and Vicki Norberg-Bohm 2005. Industrial Transformation, Environmental Policy Innovation in the United States and Europe, Cambridge: The MIT Press.

Delmas, M., \& Montiel, I. (2008). The diffusion of voluntary international management standards: responsible care, ISO 9000, and ISO 14001 in the chemical industry. Policy Studies Journal, 36(1), 65-93.

Dryzek, J. S. 1997. The politics of the earth, environmental discourses. Oxford: Oxford University Press

Fischer, K., and Schot, J. 1994, The Challenge of Going Green." Harvard Business Review, July-August, p. $47-$ 50 .

Giddens, A .1990.The Consequences of Modernity, Cambridge: Polity

Hajer, M. 1995. The Politics of Environmental Discourse: Modernisation and the Policy Process. Oxford: Oxford University Press.

Jacobs, M. 2012. Green Growth: Economic Theory and Political Discourse, WP 92 Grantham Research Institute on Climate Change and the Environment, London School of Economics and Political Science.

Jänicke, M. 2008. Ecological modernisation: new perspectives. Journal of Cleaner Production 16.5: 557-565.

Jenkins, R. 2005. Globalization, corporate social responsibility and poverty. International Affairs, 81: 525-540.

Kua H. W., 2010. CSdR Singapore - applying creative governance concept to corporate sustainability through action research, The International Journal of Social Policy Research and Development, Vol. 1, No.2, 26-35.

Lorek, S., \& Spangenberg, J. H. 2014. Sustainable consumption within a sustainable economy-beyond green growth and green economies. Journal of Cleaner Production, 63, 33-44.

Martinez-Alier, J., 2002. The environmentalism of the poor. Cheltenham, UK: Edward Elgar

Porter,M.E and Van der Linde, C. 1995. Green and Competitive: Ending the Stalemate. Harvard Business

Review, 73 (5), 120-134 .

Rands, G and Starik, M ( 2009) The Short and Glorious History of Sustainability in North American

Management Education, in Wankel, C and Stoner, J ( 2010) Management Education for Global Sustainability, 20-28, New York: Information Age Publishers

Sarkis, J., 2007. Current issues in the greening of industry: A 'sustainable' polemic. Business Strategy and the Environment, 16(3): p. 246-247.

Sarkis, J., and Gollagher, M., 2008. Of pyramids, roads and bridges: the 2007 Greening of Industry Network Conference. Business Strategy and the Environment 17.5, 289-293.

Sarkis, J., Zhu, Q., \& Lai, K. H. (2011). An organizational theoretic review of green supply chain management literature. International Journal of Production Economics, 130(1), 1-15. 
Vazquez-Brust, D. A. and Sarkis, J. 2012. Conclusion: The Green Way Forward? In: Vazquez-Brust, D.A. and Sarkis, J. eds. Green-Growth: Managing the Transition to Sustainable Capitalism: Learning by doing in EastAsia and Europe. London: Springer. 
Table 1: GIN sponsored events over the years.

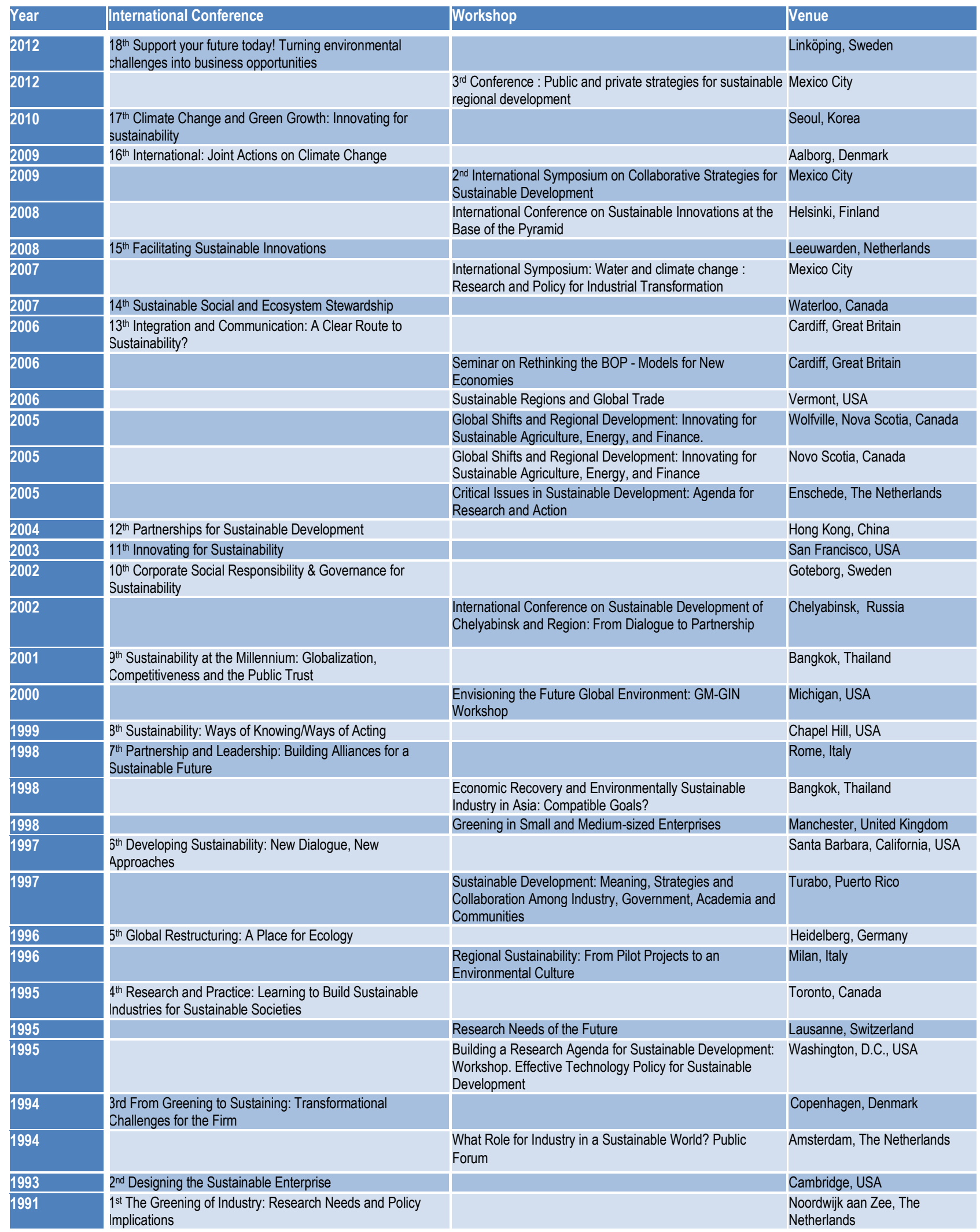


Table 2: Calendar of major 'environmental events' occurring just prior to and during the years of GIN existence.

\begin{tabular}{|c|c|}
\hline Year & Environmental Event \\
\hline 1982 & Protocol to Amend the Ramsar Convention ("Paris Protocol") \\
\hline 1987 & Montreal Protocol on Substances that Deplete the Ozone Layer \\
\hline 1987 & $\begin{array}{l}\text { Our Common Future: Report of the World Commission on Environment and Development ("Brundtland } \\
\text { Report") }\end{array}$ \\
\hline 1992 & United Nations Conference on Environment and Development (UNCED / "Earth Summit") (Agenda 21) \\
\hline 1992 & Framework Convention on Climate Change (UNFCCC) (Kyoto protocol) \\
\hline 1992 & Convention on Biological Diversity \\
\hline 1992 & Protocol on Biosafety to the Convention on Biological Diversity ("Cartagena Protocol") \\
\hline 1997 & Protocol to the UNFCCC ("Kyoto Protocol") \\
\hline 1998 & $\begin{array}{l}\text { UNECE Convention on Access to Information, Public Participation in Decision-Making and Access to } \\
\text { Justice in Environmental Matters ("Aarhus Convention") }\end{array}$ \\
\hline 1998 & $\begin{array}{l}\text { Convention on the Prior Informed Consent Procedure for Certain Hazardous Chemicals and Pesticides in } \\
\text { International Trade ("Rotterdam Convention") }\end{array}$ \\
\hline 1999 & Protocol on Water and Health to the Water Convention \\
\hline 2000 & The Cartagena Protocol on Biosafety ("Cartagena Protocol") \\
\hline 2000 & $\begin{array}{l}\text { Protocol on Liability and Compensation for Damage Resulting from Trans boundary Movements of } \\
\text { Hazardous Wastes and Their Disposal to the Basel Convention ("Basel Protocol") }\end{array}$ \\
\hline 2012 & Rio+20 - United Nations Conference on Sustainable Development \\
\hline
\end{tabular}

